\title{
AUTOMATION OF WORKPLACE ERGONOMICS SETTING BASED ON IMAGE PROCESSING
}

\author{
BOZEK, P[avol]; ONDRIGA, M[artin] \& HRDLICKOVA, Z[uzana]
}

\begin{abstract}
The article shows possibilities of obtaining anthropometrical data through the analysis of special objects in pictures. In our case, the subject of the analysis is a specific human image focused on the unique contours of the body, carrying relevant physical information about a person. The elaborating of these curves brings us information needed for defining of a workplace parameters.

Key words: image processing, human, dimensions, proposal of the workplace, a workplace in a sitting position
\end{abstract}

\section{INTRODUCTION}

The proposal of measuring system for length dimensions of the human body is based on the shape of a human body, characteristic features of the skeleton and the ability to assume different positions in space, depending on the musculoskeletal limitations of human (Rosicka et al., 2008).

\section{THE ANALYSIS OF BASICS FOR THE WORKPLACE IN THE SITTING POSITION}

The general parameters of the workplaces in SR are regulated by Decree of the National Council SR no. 542/2007 of Statute Book. Annex No. 1 entitled "The requirements for a working place depending from increased physical stress" deals with the design of working place, concretely in the sitting and standing positions. The Decree allows individual assessment of workplaces based on employees anthropometric parameters.

2.1 The required dimensions for the workplace design The required dimenssions:

A) shoulder height in the sitting position, abbreviation SHst,

B) elbow height in the sitting position, abbreviation EHst,

C) thigh height above the seat, abbreviation MTHast,

D) knee height in the sitting position, abbreviation HKst,

E) the hollow of the knee height in the sitting, abbreviation $\mathrm{FPH}$,

F) length of arm in flexion, abbreviation UAL (Hatiar \& Caganova, 2009).

The image (Fig.1) shows the location of the required dimensions of the human body. In the picture below the person is situated in the reference position according to the mentioned decree.

The unknown points:

- Point Olecraniale (ol.) - the farthest point of processus olecrani at $90^{\circ}$ flexion of the forearm.

- Femoral point (fe.) - the highest point of the thigh from the horizontal plane Basis sedens (bs.), on which a man sits and rests on the lower surfaces of her thighs.

- Point Genion superior (ges.) - the highest salient point at the top of the patella in extension of the tibia in $90^{\circ}$ flexion in the knee.

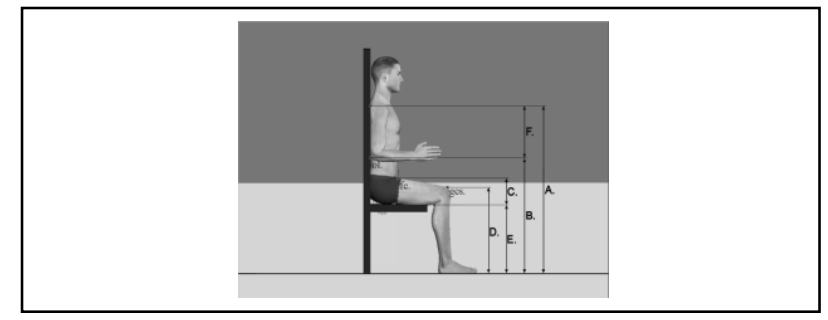

Fig. 1. The required dimensions in the reference position

The positions of other anthropometric points can be computed from informations about workplace and the parameters summarized in paragraph called as "The unknown points".

\section{PUBLISHING STEPS THE PROPOSAL OF MEASUREMENT}

3.1 New reference position

A determination of a new position for measurement (Fig. 2) occurred after a previous discussion with ergonomic professional supervisor. New reference position allows obtaining required dimension with proposed procedures for image processing.

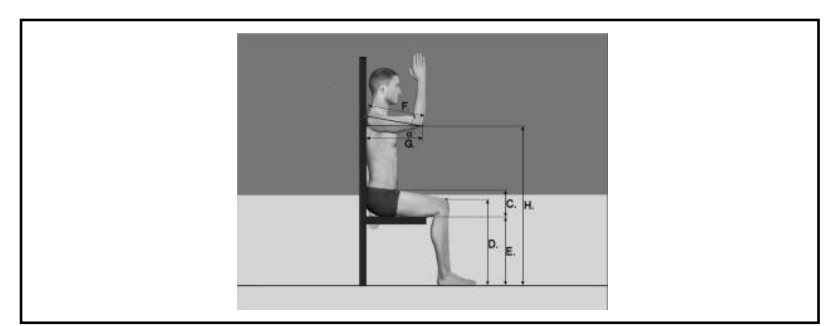

Fig. 2. The required dimensions in the new reference position

The new position differs from the original reference position with 90 degree shoulder flexion combined with 90 degree forearm flexion, as shows figure (Fig.2).

\subsection{Image requirements}

Object should be photographed isolated on a white background for creating of high contrast with human skin color, what could facilitate the process of an image segmentation. The isolation of an object will be reached by placing a white canvas under and behind the measured object. It is also needed to overexpose the canvas by lights to avoid to creating of shadows. The professional softboxs must be used, when we want to shine a person reliably (Nixon, 2002).

The delimitation of measuring area is realized with attachment of reflective identifiers on the wrist of measured person and on the fixed point of the workplace, in the expected position of the lower half of the shank (Fig. 3). Such a placement of reflective strips also defines position of all planes needed for measurement (basis, basis sedens, basis dorsalis). 
This type of workplace assumes a flexible basis (b) plane with the possibility of determining of its position.

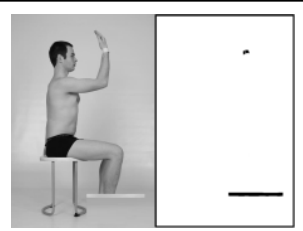

Fig. 3. The example of a image suitable for measuring and allocated reflective stripes

\subsection{Image segmentation}

The problem of object (foreground) separation from the background is solved by segmentation methods (Hlavac et al., 1999). The measured system use one of the most advanced segmentation techniques, methods Grab Cut.

The result of applying the method in an image, determined for measurement, is shown in the figure below (Fig. 4).

Grab Cut method reliably separates a measured object from its background, and thus it creates suitable conditions for further image processing (Pivarciova \& Suriansky, 2008).

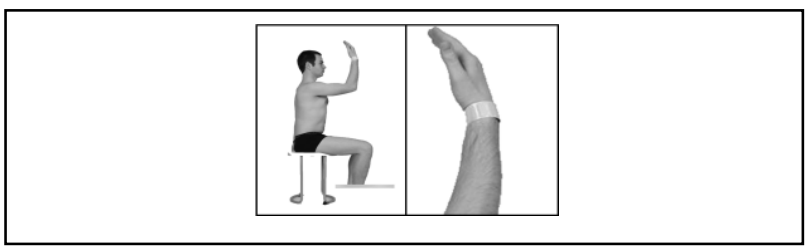

Fig. 4. The image after applying of Grab Cut method

\subsection{The delimitation of measurement area}

The delimitation of measuring area between the reflective strips are realized by direct scanning of the image, looking for positions, which correspond to the color patterns typical for the captured reflective material (Fig. 3). The next image operations will be conducted exclusively for a limited part of the picture.

The allocated measuring space will be scanned to the border line of the object from the right side. The result of this procedure is a set of discrete points in space of two-dimensional images (Fig. 5). Line points and information about location of reflective strips give us inevitable information about the proposal of a workplace.

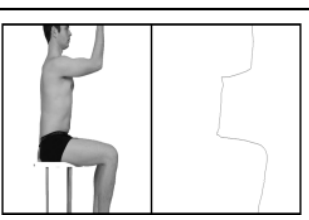

Fig. 5. The image after cutting and a set of discrete points of the edge

\subsection{The determination of anthropometric positions}

We can take into consideration several ways of determining of anthropometric positions in places, where a contour evidently changes its direction.

For detection of bending sites we tested a number of conventional approaches in the sphere of corner operators and Hough transformation. These approaches were not suitable for the specificity of a human image. The assigned locations do not always correspond with searching areas and the system was generally unreliable.

Solving of the problems bases in a searching of new approach. This new approach results in an algorithm. The accuracy and reliability of this algorithm is a starting point for a practical using.

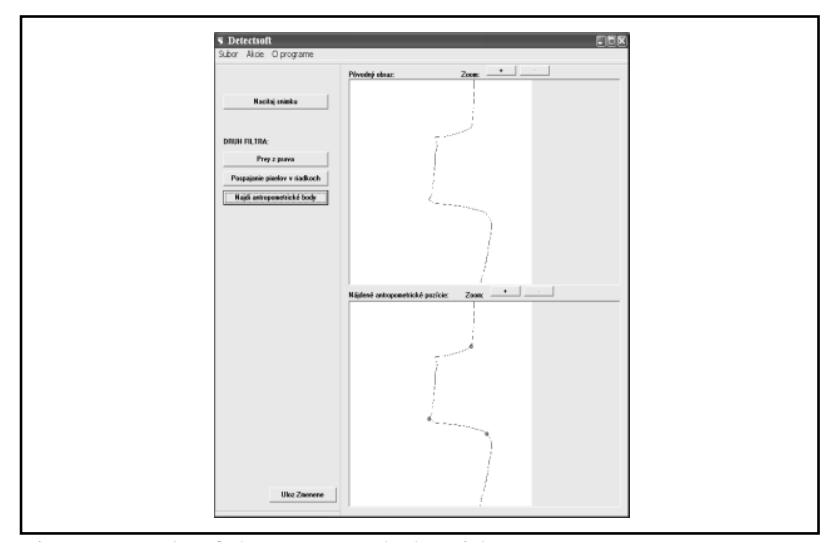

Fig. 6. Result of the proposed algorithm

The algorithm works by scanning the body contour, where monitors directional shift of modifiable groups consisting of image elements and simultaneously allows setting of quantity of these elements in a group and deviation for individual anthropometrical positions. By this way it is possible to accurate subtle deviations between measured and real values of required positions, and thus to increase the accuracy of the proposed method of measurement.

\section{CONCLUSION}

In the paper we presented a measurement procedure, which offers a solution for automated workplace designing. A measurement of required dimensions is proposed in accordance with an actual legislation, which deals with the requirements for a workplace and with limitations of increased physical activity at work and assume all its postulates. The method of dimensions measuring publish on the paper above is still in extensive development. The next step in the near future, will be implementation of the workplace based on these principles, experimental measurements, system accuracy verification and finally, putting into operation.

\section{ACKNOWLEDGEMENTS}

The contribution was elaborated within the research project KEGA project No. 3-7285-09 Contents Integration and Design of University Textbook "Specialised Robotic Systems" in Print and Interactive Modules for University of Technology in Zvolen, Trenčín University and Slovak University of Technology in Bratislava.

\section{REFERENCES}

Hatiar, K. \& Caganova, D. (2009). Workplace Dimension Adaptation to Worker as one of Tools for Increasing Human Work Effectiveness. Proceedings of the 20th International DAAAM Symposium, ISBN 978-3-90150970-4, ISSN 1726-9679, pp. 1703-1704, Vienna

Hlavac, V.; Sonka, M. \& Boyle, R. (1999). Image processing, analysis and Machine Vision, PWS Boston, ISBN 0849397745, Boston

Nixon, M. S. (2002). Feature Extraction and Image Processing. Newnes, ISBN 075065078 8, London

Pivarciova, E. \& Suriansky, J. (2008). Design and implementation of a biometric system (Návrh a realizácia biometrického systému). In: Acta Facultatis Technicae, TU Zvolen, ISSN 1336-4472, Zvolen

Rosicka, Z.; Benes, L. \& Fleissig, P. (2008). Vita in Societate Secura. In: Monographica I. 1st ed. Pardubice, 2008. 132 p. ISBN 978-80-7395-117-7, Pardubice 